\title{
Caracterização citogenética de Encyclia caximboensis (Orchidaceae) cultivadas in vitro ${ }^{(1)}$
}

\author{
GIZELLY MENDES DA SILVA(2), TATIANE LEMOS VARELLA ${ }^{(2)}$, KALIANE ZAIRA CAMACHO MAXIMILIANO DA CRUZ ${ }^{(2),}$ \\ ILIO FEALHO DE CARVALHO(2), ISANE VERA KARSBURG ${ }^{(3)}$ e MAURECILNE LEMES DA SILVA ${ }^{(2)^{*}}$
}

\begin{abstract}
RESUMO
Encyclia cachimboensis é uma espécie Amazônica endêmica da Serra do Cachimbo, localizada na divisa entre o norte do estado de Mato Grosso e o sul do Pará. Estudos sobre o cultivo in vitro e a caracterização citogenética da espécie ainda são escassos. O objetivo do trabalho foi realizar a caracterização citogenética e a identificação das Regiões Organizadoras de Nucléolos (RONs) da espécie Encyclia caximboensis cultivadas in vitro. Sementes de E. caximboensis foram desinfestadas utilizando-se de uma seringa e, posteriormente cultivadas em meio de MS na ausência de regulador de crescimento. A germinação iniciou-se aos 20 dias cultivo com o desenvolvimento dos protocormos e, após 90 dias foram obtidas 40.500 plântulas. Para a caracterização citogenética, ápices radiculares de plântulas com 180 dias de cultivo in vitro foram submetidos ao tratamento de bloqueio utilizando solução de trifluralin $3 \mu \mathrm{M}$, sendo fixados em solução metanol-ácido acético (PA) na proporção de 3:1. Os meristemas foram submetidos à digestão enzimática e fixados em solução metanol-ácido acético (3:1) e as lâminas foram coradas com Giemsa a 5\%. No bandeamento AgNOR, lâminas com 20 dias de envelhecimento foram cobertas com solução de nitrato de prata $\left(\mathrm{AgNO}_{3}\right) 50 \%$ e incubadas por 19 horas. Os resultados indicam que a espécie $E$. caximboensis possui complemento diplóide com $2 \mathrm{n}=24$ com todos os cromossomos do tipo metacêntricos. O tamanho dos cromossomos variaram entre 1,88 a 0,66 $\mu \mathrm{m}$ de tamanho, com RNOs simples em pequenos blocos localizados na região proximal do $3^{\circ}$ par cromossômico.
\end{abstract}

Palavras-chave: micropropagação; orquídea; cromossomos; região organizadora de nucléolo.

\begin{abstract}
Cytogenetic characterization of Encyclia caximboensis cultivated in vitro (Orchidaceae)

Encyclia caximboensis is an Amazonian species endemic to the Serra do Cachimbo, which is located between the northern of the Mato Grosso state and the southern part of Para state. Studies reporting in vitro cultivation and cytogenetic characterization of this species are still scarce. Therefore, the objective of this work was to determine the cytogenetic characteristics and to identify the nucleolar organizer regions (NORs) of the species E. Caximboensis, cultivated in vitro. Seeds of E. caximboensis were disinfected using a syringe and subsequently cultivated in MS medium without growth regulators. The germination started after 20 days of culture, with the development of protocorm and 40,500 seedlings were obtained after 90 days of culture. To perform the cytogenetic characterization, root tips of 180-day-old seedlings were submitted to blocking treatment using $3 \mu \mathrm{M}$ trifluralin and then fixed in methanol-acetic acid solution, $3: 1(\mathrm{v} / \mathrm{v})$. The meristems were submitted to enzymatic digestion, fixed in methanol-acetic acid solution, 3:1 (v/v) and the slides were stained using 5\% Giemsa solution. Ag-NOR banding was carried out on 20-day-old slides by incubation in $50 \%$ silver nitrate solution $\left(\mathrm{AgNO}_{3}\right)$ for 19 hours. The results indicated that $E$. caximboensis has $2 \mathrm{n}=2 \mathrm{x}=24$ with all metacentric type chromosomes, ranging from 1.88 to $0.66 \mu \mathrm{m}$ in length, with simple NORs in small blocks localized in the proximal region of the third chromosome pair.
\end{abstract}

Keywords: micropropagation; orchid; chromosomes; nucleolus organizer regions.

\section{INTRODUÇÃO}

A família Orchidaceae compreende uma das maiores famílias entre as fanerógamas e apresenta grande variação morfológica, cromossômica e alta diversidade genética (DRESSLER, 2005; ARDITTI, 2008; CHUGH et al., 2009) e, no Brasil ocorre aproximadamente 235 gêneros e 2.419 espécies (BARROS et al., 2011). A subfamília Epidendroideae é a de maior representatividade, com cerca de 650 gêneros e 18.000 espécies, abrangendo mais gêneros e espécies do que todas as outras subfamílias juntas (PRIDGEON et al., 2005). A subtribo Laeliinae compreende aproximadamente 1.500 espécies (DRESSLER, 1993) distribuídas em 39 gêneros (VAN DEN BERG, 2005) e é amplamente distribuída pelas áreas tropicais e subtropicais das Américas e do Caribe. O gênero Encyclia pertence à subtribo Laeliinae e é constituído por 56 espécies no Brasil, sendo 42 endêmicas, como é o caso da espécie Encyclia caximboensis, que é endêmica da Serra do Cachimbo localizada no norte do estado de Mato Grosso e o sul do Pará (MILLIKEN et al., 2010).

Embora o cultivo de orquídeas tenha contribuído para tornar o Brasil conhecido internacionalmente por suas plantas exóticas, essas em geral são obtidas, quase sempre pelo extrativismo predatório das matas tropicais (KÄMPF, 1997). Atualmente, inúmeras variedades estão em risco, ou já foram extintas, e em muitos casos não foram estudadas ou classificadas (REZENDE et al., 2009). Em condições naturais, a propagação das orquídeas se dá pela proliferação de mudas laterais ou pela disseminação

(1) Recebido em 29/06/2014 e aceito em 16/10/2015

(2) Universidade do Estado de Mato Grosso (UNEMAT), Tangará da Serra-MT, Brasil. * Autor correspondente: maurecilne@gmail.com 
natural de suas sementes. As sementes das orquídeas não possuem endosperma, necessitando de associações com fungos micorrízicos para cada espécie. Tais características reduzem significativamente as chances de um indivíduo chegar à fase adulta em condições naturais (COSTA et al., 2009). Diante da demanda de orquídeas para o comércio florícola mundial, o cultivo in vitro representa uma alternativa para contornar os obstáculos que limitam a propagação convencional (MOREIRA et al., 2007). No gênero Encyclia ainda existem poucos relatos do cultivo in vitro (STENBERG e KANE, 1998).

Em termos citológicos, a subfamília Epidendroideae apresenta grande variação cromossômica, de 2 n=24 em Malaxis pubescens a $2 \mathrm{n}=240 \mathrm{em}$ Epidendrum cinnabarinum, que também é a maior número cromossômico para a família (FELIX e GUERRA, 2010). O gênero Encyclia apresenta uma grande carência em estudos cariológicos, sendo que das 154 espécies pertencentes a este gênero, apenas sete apresentam registros cromossômicos (FELIX e GUERRA, 2010). Daviña et al. (2009) destacam que a evolução dos cromossomos na família Orchidaceae ainda permanece inconclusiva. Essa escassez de dados constitui uma lacuna importante para o entendimento dos mecanismos de evolução cariotípica ocorrentes nesse grupo de plantas (DAVIÑA et al., 2009). O conhecimento do número cromossômico e do comportamento meiótico, associados com conhecimentos sobre os padrões de florescimento, frutificação e germinação das sementes são importantes para a compreensão do processo evolutivo e sucesso reprodutivo de qualquer espécie vegetal superior (BATTISTIN et al., 2012).

Diante do acima exposto, o objetivo do trabalho foi realizar a caracterização citogenética e a identificação das Regiões Organizadoras de Nucléolos (RONs) de plantas da espécie E. caximboensis cultivadas in vitro.

\section{MATERIAL E MÉTODOS}

\section{Obtenção do material vegetal}

Flores de E. caximboensis (Fig. 1A) foram polinizadas manualmente. Duas cápsulas maduras recém abertas foram coletadas e, as sementes desinfestadas sob condições assépticas em câmara de fluxo laminar, com o auxílio de seringa descartável. As sementes foram imersas em álcool etílico a $70 \%\left(\mathrm{v} \mathrm{v}^{-1}\right)$ por 1 min., em seguida mantidas em solução de hipoclorito de sódio comercial a $1 \%$ com a adição de 3 gotas de Tween-20, durante 10 min. e seguido de 4 lavagens consecutivas em água destilada e esterilizada.

As sementes foram inoculadas em meio de germinação semi sólido, constituído de sais básicos de MS (MURASHIGE e SKOOG, 1962) em 30 frascos de cultivo, sendo inoculado $1 \mathrm{~mL}$ de solução (água + sementes) em cada frasco. O meio foi suplementado com vitamina B5 (GAMBORG et al., 1968), 3\% de sacarose, $0,01 \%$ de inositol, e $7 \%$ de ágar como agente gelificante. $\mathrm{O} \mathrm{pH}$ do meio de cultura foi ajustado para 5,7 $\pm 0,1$ antes da autoclavagem. Os frascos foram vedados com filme PVC esticável de 9-10 $\mu \mathrm{m}$ de poro (Goodyear, Brasil). As culturas foram mantidas em sala de cultivo, com temperatura de 25 $\pm 2{ }^{\circ} \mathrm{C}$, fotoperíodo de 16 horas de luz e 8 horas de escuro, e irradiância de $36 \mu \mathrm{molm}^{2} \mathrm{~s}^{-1}$ providas por duas lâmpadas fluorescentes (Luz do Dia Especial, 20 W, Osram, Brasil). Aos 90 dias de cultivo in vitro as plantas obtidas foram contadas manualmente.

\section{Caracterização citogenética}

Os cromossomos foram obtidos utilizando ápices radiculares das plântulas com 180 dias de cultivo in vitro (Figura 1C). O tratamento de bloqueio dos processos de divisão celular foi realizado através da permanência dos meristemas em uma solução de trifluralin na concentração de $3 \mu \mathrm{M}$ por 18 horas a $4{ }^{\circ} \mathrm{C}$. Em seguida, os meristemas foram lavados em água destilada e fixados em solução metanol-ácido acético (PA) na proporção de $3: 1$ a $4{ }^{\circ} \mathrm{C}$ por um período de 24 horas. Os meristemas foram retirados da solução fixadora, submetidos à lavagem com água destilada e transferidos para tubos de microcentrífuga contendo 200 $\mu \mathrm{L}$ da enzima pectinase na concentração de $3 \mu \mathrm{M}$, onde permaneceu por 50 minutos a $36{ }^{\circ} \mathrm{C}$ em banho Maria. Após a digestão enzimática, o material foi lavado e fixado em solução metanol ácido acético $(3: 1)$ por 24 horas a $4{ }^{\circ} \mathrm{C}$.

As lâminas foram confeccionadas de acordo com Carvalho e Saraiva (1993), e coradas com Giemsa a 5\% por 3 minutos, lavadas em água destilada e secas em temperatura ambiente.

As metáfases de interesse foram fotodocumentadas em um microscópio Fotômico Binocular (Leica ICC 50) acoplado a um computador com software LAZ EZ V1. 7.0. As lâminas foram analisadas através do programa Image SXM (BARRET, 2002) de domínio público. Os braços de cada cromossomo foram medidos em pixels e convertidos em escala de micrômetros. Os cromossomos foram classificados de acordo com o índice centromérico $\left(\mathrm{I} C=\mathrm{BC} \times 100 \mathrm{~T}^{-1}\right)$, sendo: ÍC = índice centromérico, $\mathrm{BC}=$ comprimento do braço curto; $\mathrm{T}=$ comprimento cromossômico total e a razão entre os braços (r) que foram determinados segundo os critérios propostos por Levan et al. (1964) e revisados por Guerra (1986).

\section{Identificação de Regiões Organizadoras de Nucléolo (RONs)}

Após 20 dias de envelhecimento, as lâminas foram submetidas ao bandeamento Ag-NOR segundo Funaki et al. (1975). A solução de nitrato de prata $\left(\mathrm{AgNO}_{3}\right) 50 \%$ foi gotejada sobre cada lâmina e depois cobertas com lamínula e mantidas em câmara úmida e escura a $34^{\circ} \mathrm{C}$, durante 19 horas. Decorrido o tempo de incubação, as lamínulas foram removidas com jato de água e as lâminas foram lavadas em água corrente por 2 minutos, em seguida em água destilada por 1 minuto. A análise das lâminas foi realizada com uso de microscópio OlympusTM, iluminação de campo claro, usando a objetiva de 100 x (imersão a óleo). As imagens foram capturadas pelo programa ACDsee e digitalizadas pelo Corel Photo-Paint X3 (versão13). 


\section{RESULTADOS E DISCUSSÃO}

\section{Cultivo in vitro}

A germinação das sementes de E. caximboensis variou entre 20 e 30 dias de cultivo in vitro (Figura 1B) no desenvolvimento dos protocormos. A conversão dos protocormos em plântulas, ou seja, a expansão das folhas e desenvolvimento dos primórdios radiculares ocorreu aproximadamente aos 60 dias e, aos 90 dias foram obtidas 40.500 plântulas (Figura 1D).

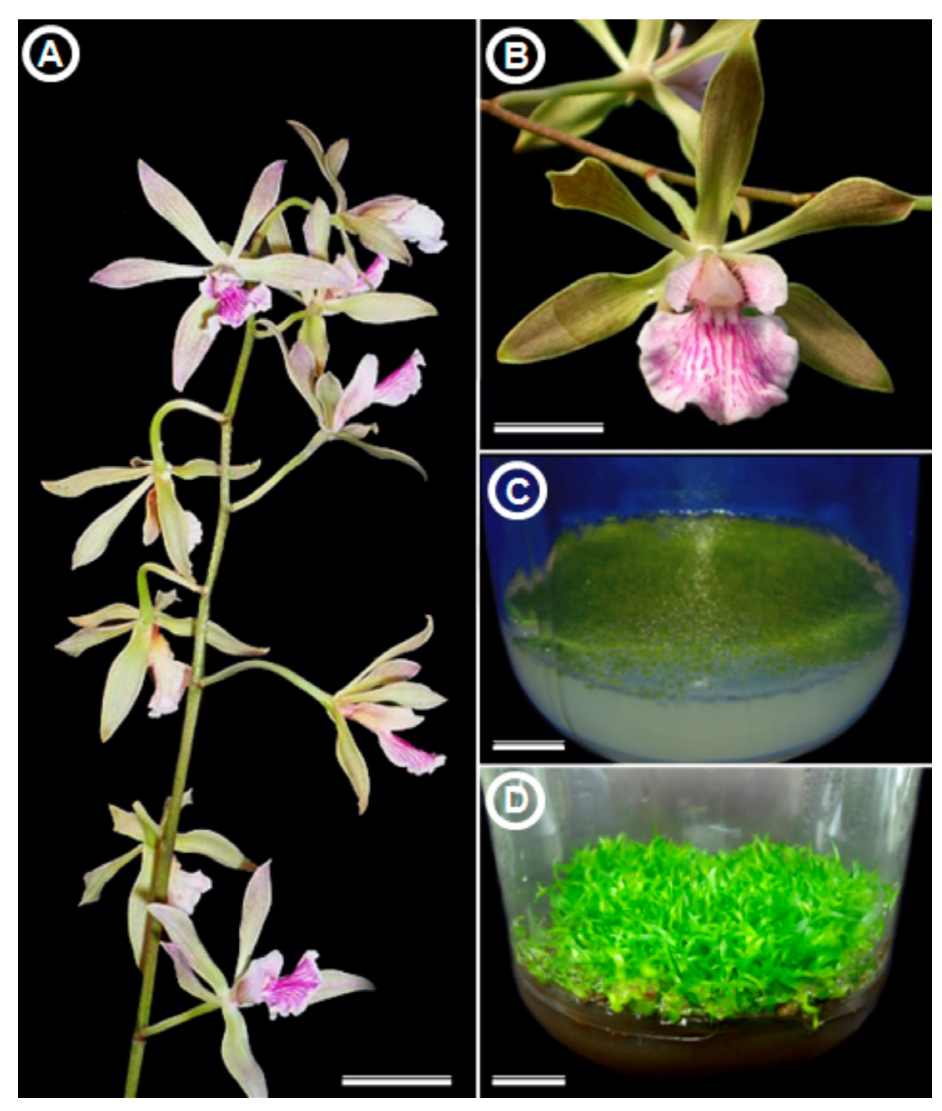

Figura 1. Flor e cultivo in vitro de E. caximboensis. Haste floral (A); (B) Germinação in vitro das sementes e o desenvolvimento de protocormos. Bar. 2 mm. (C) Plântula cultivada aos 180 dias. As setas indicam os ápices radiculares utilizados na caracterização citogenética. Bar. $15 \mathrm{~mm}$. (D) Plântulas após 60 dias de cultivo in vitro. Bar. $10 \mathrm{~mm}$.

Figure 1. Flower and in vitro cultivation of E. caximboensis (A) Stem floral (B) Flower in detail In vitro germination of seeds in the protocorm of development. Bar $=2 \mathrm{~mm}$.; (C) Seedling grown to 90 days. The arrows indicate the root apices used for cytogenetics Bar $=15 \mathrm{~mm}$; (D) Seedlings after 60 days in vitro cultivation Bar $=10 \mathrm{~mm}$.

O cultivo in vitro é considerado o mais efetivo método para a multiplicação em massa de orquídeas ameaçadas de extinção (THAN et al., 2011). Atualmente diversos estudos têm sido desenvolvidos com a finalidade de definir meios de cultivo mais adequados para propagar cada espécie de orquídea, assim como incrementar a viabilidade genética e resgatar espécies raras e em risco de extinção (STEPHENSON e FAHEY, 2004).

Vários trabalhos vêm demonstrando a eficiência do meio de cultura MS na micropropagação de orquídeas (UNEMOTO, 2007; RUÍZ et al., 2008; REZENDE et al., 2009; FARIA et al., 2012). O grande número de indivíduos obtidos nestas condições in vitro pode estar relacionado com as características do meio de MS, pois disponibiliza ao explante elevada concentração de sais minerais e proporcionam condições ideais para a germinação, o desenvolvimento e a produção em larga escala de plantas de orquídeas.

\section{Caracterização citogenética}

Nas análises citogenéticas, as células em metáfases apresentaram cromossomos com distinta condensação da cromatina, bem distribuídos, na ausência de sobreposições, citoplasma e deformidades da cromatina. Através das análises verificou-se que a espécie E. caximboensis possui $2 \mathrm{n}=24$ cromossomos (Figura 2), variando de 1,88 a $0,66 \mu \mathrm{m}$ de tamanho (Tabela 1), com RON simples em pequenos blocos na região proximal do $3^{\circ}$ par cromossômico (Figura 2). 
Tabela 1. Medidas e morfologia dos cromossomos de E. caximboensis de acordo com a posição do centrômero. Table 1. Measures and morphology of the chromosomes of E. caximboensis of according to the position of the centromere.

\begin{tabular}{|c|c|c|c|c|c|c|}
\hline \multirow{2}{*}{ Cromossomo } & \multirow{2}{*}{$\begin{array}{c}\text { Comprimento } \\
\text { total }(\mu \mathrm{m})\end{array}$} & \multicolumn{2}{|c|}{$\operatorname{Braço}(\mu \mathrm{m})$} & \multirow{2}{*}{$\begin{array}{l}\text { Razão entre os } \\
\text { braços }\end{array}$} & \multirow{2}{*}{$\begin{array}{c}\text { Índice } \\
\text { Centromérico (IC) }\end{array}$} & \multirow{2}{*}{$\begin{array}{c}\text { Morfologia } \\
\text { Cromossomo }\end{array}$} \\
\hline & & Curto & Longo & & & \\
\hline 1 & 1,88 & 0,92 & 0,96 & 1,04 & 48,93 & M \\
\hline 3 & 1,43 & 0,59 & 0,84 & 1,42 & 41,26 & M \\
\hline 5 & 1,40 & 0,62 & 0,78 & 1,26 & 44,28 & M \\
\hline 2 & 1,27 & 0,58 & 0,69 & 1,19 & 45,67 & M \\
\hline 6 & 1,26 & 0,63 & 0,63 & 1,00 & 50,00 & M \\
\hline 4 & 1,10 & 0,44 & 0,66 & 1,50 & 40,00 & $\mathrm{M}$ \\
\hline 7 & 0,92 & 0,45 & 0,47 & 1,04 & 48,91 & M \\
\hline 8 & 0,89 & 0,43 & 0,46 & 1,07 & 48,31 & M \\
\hline 10 & 0,78 & 0,33 & 0,45 & 1,36 & 42,31 & M \\
\hline 9 & 0,75 & 0,32 & 0,43 & 1,34 & 42,66 & M \\
\hline 12 & 0,66 & 0,32 & 0,34 & 1,06 & 48,48 & M \\
\hline
\end{tabular}

O número cromossômico básico da família Orchidaceae ainda é incerto. Porém, a frequente ocorrência de $\mathrm{n}=10$ e $\mathrm{n}=20$ na família, pode-se determinar que $\mathrm{x}=10$ como sendo o número básico mais provável (DODSON, 1957). O número básico de cada gênero é identificado como o número haplóide que mais parcimoniosamente explica a variabilidade cromossômica estabelecida no táxon (GUERRA, 2000). Desta forma é possível indicar o número que, mais provavelmente, representa o complemento haplóide original de cada gênero (CONCEIÇÃO e BARBOSA, 2007).

Os resultados obtidos neste trabalho, ou seja, que o complemento diplóide modal de E. caximboensis é 2 n $=$ 24 , diverge com o descrito na literatura, a qual relata que em geral as espécies pertencentes à subtribo Laeliinae apresentam $2 \mathrm{n}=40$, tendo $\mathrm{x}=20$ como número básico Felix e Guerra (2010) e sugerem que a evolução desta subtribo tenha sido por poliploidia e Loveless e Hamrick (1984) citam a ação conjunta de mutação, migração, seleção e deriva genética como outros fatores que podem ocasionar alterações no número e estrutura do conjunto cromossômico das espécies de orquídeas.

A identificação de Regiões Organizadoras de Nucléolo (RONs) também constitui uma importante característica para o estudo da evolução das plantas, que em conjunto com a análise da variação cromossômica permitem o entendimento de variações genéticas envolvidas na evolução de um grupo e a delimitação taxonômica das espécies (PEDROSA et al., 1999; COZZOLLINO et al., 2004; KOEHLER et al., 2008).

Pelo bandeamento Ag-RON identificou proteínas com atividade transcricional dos genes rDNA pela impregnação da prata nos cromossomos da espécie E. caximboensis, ou seja, ou segmentos de DNA que transcrevem o RNA ribossômico (PIEROZZI, 2007). A caracterização cromossômica fornece informações imprescindíveis para verificar as ocorrências de descontinuidades genéticas dentro e entre as espécies, e contribuem para o entendimento da relação filogenética em todos os níveis taxonômicos.

\section{CONCLUSÃO}

A germinação das sementes de E. caximboensis variou entre 20 e 30 dias de cultivo in vitro, sendo que a conversão em plântulas acorreu em aproximadamente 60 dias e com 90 dias foram obtidas $40.500 \mathrm{com} \pm 2 \mathrm{~cm}$ de comprimento. O complemento diplóide de E. caximboensis obtido foi de $2 n=24$. Os cromossomos foram do tipo metacêntricos, variando de $1,88 \mu \mathrm{m}$ a $0,66 \mu \mathrm{m}$ de comprimento e as RONs simples localizadas na região proximal do $3^{\circ}$ par cromossômico. 


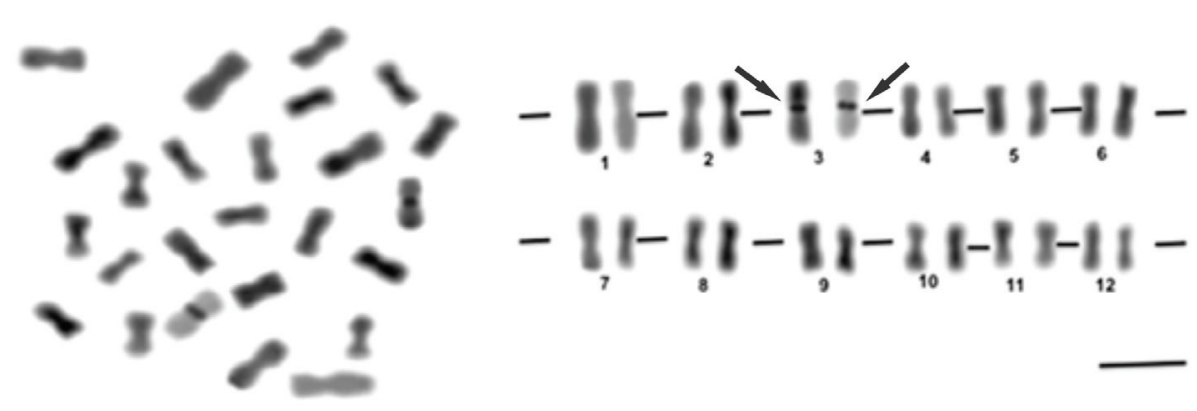

Figura 2. Metáfase e cariótipo da espécie E. caximboensis $(2 \mathrm{n}=24)$, evidenciando Regiões Organizadoras de Nucléolo (RON) simples em pequenos blocos na região mediana do $3^{\circ}$ par cromossômico. Barra $=5 \mu \mathrm{m}$ Figure 2. Metaphase and karyotype E. caximboensis species $(2 n=24)$, evidencing the Nucleolus Organizing Regions (RON) simple in small blocks in the midline of the 3rd chromosome pair. Bar $=5 \mu m$

\section{AGRADECIMENTOS}

Os autores agradecem ao Orquidário Chapada dos Parecis/MT que gentilmente forneceram as sementes de E. caximboensis. A Fundação de Amparo à Pesquisa do Estado de Mato Grosso/Fapemat pela concessão da bolsa de Iniciação Científica.

\section{REFERÊNCIAS}

ARDITTI, J. Micropropagation of orchids. 2 ed. Oxford: Wiley-Blackwell, 2008, 1560p.

BARRETT, S.D. Software for scanning microscopy. Royal Microscopy Society, Oxford, v.37, n.3, p.7-14, 2002.

BARROS, F.; VINHOS, F.; RODRIGUES, V.T.; FRAGA, C.N.; PESSOA, E.M. Orchidaceae. Lista de Espécies da Flora do Brasil. Jardim Botânico do Rio de Janeiro. 2011. Disponível em: <http://floradobrasil.jbrj.gov. br/2015/FB031788>. Acesso em: 15 de maio de 2015.

BATTISTIN, A.; ALMEIDA, A.L.S.M.; GONÇALVES, R.S.; FERMINO, M.H.; SILVEIRA, J.R.P.; BUSNELLO, A.C.; PASQUETTI, M.V. Germinação das sementes e análise citogenética em duas espécies de palmeiras. Revista Brasileira de Horticultura Ornamental, Campinas, v.18, n.1, p.79-84, 2012.

CARVALHO, C.R.; SARAIVA, L.S. An air drying technique for maize chromosomes without enzymatic maceration. Biotechnic \& Histochemistry, Louisville, v.68, n.1, p.142-145, 1993.

CHUGH, S.; GUHA, S.; RAO, I.U. Micropropagation of orchids: a review on the potential of different explants. Scientia Horticulturae, Amsterdam, v.122, n.1, p.507-520, 2009.

CONCEIÇÃO, L.P.; BARBOSA, L.V. Análise citogenética de espécies de Orchidaceae de ocorrência nas dunas do Abaete (Salvador, BA - Brasil). Terra e Cultura, Londrina, v.23, n.44, p.93-98, 2007.
COSTA, M.A.P.C.; PEREIRA, M.J.; ROCHA, M.A.; HANSEN, D.S.; ALVES, R.M.O; SOUZA, E.H.; GARCIA, F.R. Micropropagação de orquídeas. JUNGHANS, T.G.; SOUZA, A.S. (Eds.). Aspectos práticos da micropropagação de plantas. v.1. Cruz das Almas: Embrapa, Bahia. 2009. p.351-370

COZZOLINO, S.; D'EMERICO, S.; WIDMER, A. Evidence for reproductive isolate selection in Mediterranean orchids: karyotype differences compensate for the lack of pollinator specificity. Proceedings of the Royal Society B: Biological Sciences, London, v. 271, n.1, p.259-262, 2004.

DAVIÑA， J.R.; GRABIELE， M.; CERUTTI， J.C.; HOJSGAARD, D.H.; ALMADA, R.D.; INSAURRALDE, I.S.E.; HONFI, A.I. Chromosome studies in Orchidaceae from Argentina. Genetics and Molecular Biology, Ribeirão Preto, v.32, n.1, p.811-821, 2009.

DODSON, C.H. Chromosome number in Oncidium and allied genera. American Orchid Society Bulletin, USA, v.26, n.1, p.323-330, 1957.

DRESSLER, R.L. How many orchid species? Selbyana, Portland, v.26, n.1, p.155-158, 2005.

DRESSLER, R.L. Phylogeny and classification of the orchid family. Portland, OR: Dioscorides Press, 1993, 321p.

FARIA, R.T.; ASSIS A.M.; UNEMOTO L.K.; CARVALHO J.F.R.P. Produção de orquídeas em laboratório. $1^{\mathrm{a}}$ ed. Londrina: Editora Mecenas, 2012, 124p.

FELIX, L.P.; GUERRA, M. Variation in chromosome number and the basic number of subfamily Epidendroideae (Orchidaceae). Botanical Journal of the Linnean Society, London, v.163, n.1, p.234-278, 2010. Doi: 10.1111/j.10958339.2010.01059.x

FUNAKI, K.; MATSUI, S.; SASAKI, M. Location of nucleolar organizers in animal and plant chromosomes by means of an improved N-banding technique. Chromosoma, Berlin, v.49, n.1, p.357-370, 1975. 
GAMBORG, O.L.; MILLER, R.A.; OJIMA, K. Nutrient requirements of suspension cultures of soybean root cells. Experimental Cell Research, Sweden, v.50, n.1, p.151$158,1968$.

GUERRA, M. Patterns of heterochromatin distribution in plant chromosomes. Genetics and Molecular Biology, Ribeirão Preto, v.23, n.4, p.1029-1041, 2000. Doi 10.1590/ S1415-47572000000400049

GUERRA, M.S. Reviewing the chromosome nomenclature of Levan et al. Revista Brasileira de Genética, Ribeirão Preto, v.9, n.4, p.741-743, 1986.

KÄMPF, A.N.A. Floricultura brasileira em números. Revista Brasileira de Horticultura Ornamental, Campinas, S.1., v.3, p.1-7, 1997.

KOEHLER, S.; CABRAL, J.S.; WHITTEN, W.M.; WILLIAMS, N.H.; SINGER, R.B.; NEUBIG, K.M.; GUERRA, M.; SOUZA, A.P.; AMARAL1, M.C.E. Molecular phylogeny of the neotropical genus Christensonella (Orchidaceae, Maxillariinae): Species delimitation and insights into chromosome evolution. Annals of Botany, London, v.102, n.4, p.491-507, 2008. Doi: $10.1093 / \mathrm{aob} / \mathrm{mcn} 128$

LEVAN, A.; FREDGA, A.; SANDERBERG, A.A. Nomenclature for centromeric position in chromosome. Hereditas, New York, v.52, n.2, p.201-220, 1964.

LOVELESS, M.D.; HAMRICK, J.L. Ecological determinants of genetic structure in plant population. Annual Review of Ecology and Systematics, USA, v.15, n.1, p.65-95, 1984

MILLIKEN, W.; ZAPPI, D.; SASAKI, D.; HOPKINS, M.; PENNINGTON, R.T. Amazon vegetation: how much dont we know and how much doit matter? Kew Bulletin, Kew, v.65, p.691-709, 2010.

MOREIRA, B.M.T.; TOMBA, E.C.; ZONETTI, P.C. Crescimento in vitro de plântulas de orquídea (Laelia purpurata Lindl var. venosa x Cattleya warneri $\mathrm{T}$. Moore alba) sob diferentes concentrações de sacarose e frutose. SaBios: Revista de Saúde e Biologia, Campo Mourão, v.2, n.2, p.16-21, 2007.

MURASHIGE, T.; SKOOG, F. A revised medium for rapid growth and bioassays with tobacco tissue cultures. Physiologia Plantarum, Copenhagen, v.15, p.473-497, 1962.

PABST, G.F.J.; DUNGS, F. Orchidaceae Brasiliensis. 1 ed. Hildesheim: Kurt Schmersow, 1975, 408p.
PEDROSA, A.; GITAÍ, J.; SILVA, A.E.B.; FELIX, L.P.; GUERRA, M. Citogenética de angiospermas coletadas em Pernambuco - V. Acta Botanica Brasilica, Belo Horizonte, v.13, n.1, p.49-60, 1999.

PIEROZZI, N.I. Caracterização dos cromossomos mitóticos de espécies diplóides de café por técnicas convencionais e de bandamento-C e -NOR. O Agronômico, Campinas, v.59, n.1, p.65, 2007.

PRIDGEON, A.M.; CRIBB, P.J.; CHASE, M.W.; RASMUSSEN, F.N. Genera Orchidacearum, 1 ed. New York: Oxford University Press, 2005. 672p.

REZENDE, J.C.; FERREIRA, E.A.; PASQUAL, M.; VILLA, F.; SANTOS, F.C. Desenvolvimento in vitro de Cattleya loddigesii sp.: adição de reguladores de crescimento e sacarose. Agrarian, Dourados, v.2, n.1, p.99-114, 2009.

RUÍZ, B.C.; LAGUNA, C.A.; IGLESIAS, A.L.G.; DAMON, A.; MARÍN, H.T.N.J.; AZPÍROZ, R.H.S.; MORENO, M.J.L. Germinación in vitro de semillas de Encyclia adenocaula (La Llave \& Lex.) Schltr (Orchidaceae). Revista Internacional de Botanica Experimental, Buenos Aires, v.77, n.1, p.203-215, 2008.

STENBERG, M.L.; KANE, M.E. In vitro seed germination and greenhouse cultivation of Encyclia boothiana var. erytriniodes, an endangered Florida orchid. Lindleyana, USA, v.13, n.l, p.101-112, 1998.

STEPHENSON, K.K.; FAHEY, J.W. Development of tissue culture methods for the rescue and propagation of endangered Moringa spp. germoplasma. Economic Botany, New York, v.58 (s.1.): 116-124, 2004.

THAN, M.M.M.; PAL, A.; JHA, S. Chromosome number and modal karyotype in a polysomatic endangered orchid, Bulbophyllum auricomum Lindl., the Royal Flower of Myanmar. Plant Systematics and Evolution, Viena, v.294, n.1., p.167-175, 2011

UNEMOTO, L.K.; FARIA, R.T.; VIEIRA, A.O.S.; DALIO, R.J.D. Propagação in vitro de orquídeas brasileiras em meio de cultura simplificado. Revista Brasileira de Agrociência, Pelotas, v.13 (s.1), p.267-269, 2007.

VAN DEN BERG, C.; GOLDMAN, D.H.; FREUDENSTEIN, J.V.; PRIDGEON, A.M.; CAMERON, K.M.; CHASE, M.W. An overview of the phylogenetic relantionships within Epidendroideae inferred from multiple DNA regions and recircumscription of Epidendrae and Arethuseae (Orchidaceae). American Journal of Botany, USA, v.92, n.4, 613-624, 2005. Doi 10.3732/ ajb.92.4.613 